\title{
BRINCADEIRA E AMIZADE: Um estudo com alemães, brasileiros e libaneses
}

\author{
Play and friendship: A study with germans, brazilians and lebanese
}

\begin{abstract}
Lorena Q ueiroz Merizio ${ }^{\text {a }}$, Claudia Broetto Rossetti ${ }^{b}$
${ }^{a}$ Mestre em Psicologia pela Universidade Federal do Vitória, ES - Brasil, e-mail: lorenamerizio@ yahoo.com.br

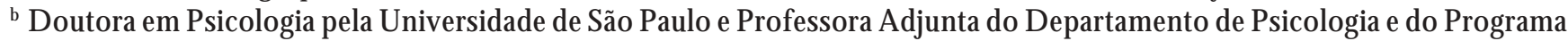
de Pós-Graduação em Psicologia da Universidade Federal do Espírito Santo (UFES), Vitória, ES - Brasil, e-mail: cbroetto.ufes@gmail.com
\end{abstract}

\section{Resumo}

O brincar é universal e possui caráter específico, de modo que o ritmo da brincadeira, sua dinâmica e suas regras ajustam-se às condições onde ocorre. As brincadeiras possuem características que facilitam as interações sociais, favorecendo a construção de amizades. D e maneira geral, a brincadeira pressupõe relação social e interação, sendo que a exploração lúdica permite a formação de atitudes, a compreensão de valores morais, o respeito às regras previamente estabelecidas socialmente, e a experiência de competir e de colaborar, dentre outros aspectos. 0 objetivo da presente pesquisa foi descrever, comparar e analisar a brincadeira e sua ligação com a formação de amizades, segundo alemães, brasileiros e libaneses, a partir de suas recordações. Realizaram-se entrevistas semiestruturadas em profundidade com quatro alemães, quatro brasileiros e quatro libaneses que vivenciaram a infância em seus países de origem e que, atualmente, residem no Brasil. Constatou-se que a brincadeira media redes de amizade e auxilia na manutenção desses relacionamentos, independente das tradições culturais. Acredita-se que investigar a díade brincadeira-amizade sob a luz de aspectos culturais específicos, possibilita ao indivíduo a constituição de si mesmo enquanto sujeito imerso no ambiente sociocultural. Assim, a expressão humana por meio do lúdico demonstra que o brincar é eficaz nos relacionamentos interpessoais de amizade, contribuindo para a formação do ser humano.

Palavras-chave: Brincadeira; Amizade; Cultura. 


\begin{abstract}
The play estimates social learning, develops and renews in one determined culture. Play is universal and possesses specific character in way that the rhythm of the entertainment, its dynamics and its rules adjust the conditions to it occurs. The playful have characteristics that facilitate the social interactions favoring the formation of friends relationships. In general way, play estimates social relation and interaction, being that the playful exploration allows the formation of attitudes, the understanding of moral values, the respect to the rules previously established socially and the experience to compete and collaborate, among other aspects. The purpose of the present research was to describe, compare and analyze the play and its linking with the formation of friendships according to Germans, Brazilians and Lebanese. Interviews were structuralized in depth with four Germans, four Brazilians and four Lebanese that had been become fulfilled who had lived infancy in its native countries and now lives in Brazil. It was evidenced that the joke measured friendship nets and supports in the maintenance of these relationships, independent of the culture traditions. One gives credit that to investigate play and friendship in specific cultural aspects, it makes possible to the individual while the exactly immersed construction of subject itself in the partner-cultural environment. Thus, the expression human being by means of the playful one demonstrates that playing is efficient in the interpersonal relations of friendship, contributing for the formation of the human.
\end{abstract}

Keywords: Play; Friendship; Culture.

\section{INTRODUÇÃO}

As recordações trazidas por gerações passadas reafirmam 0 que a ciência vem tentando comprovar ao longo dos anos e que é explicitado por Bosi (2004): a memória dos idosos desdobra e alarga de tal modo os horizontes da cultura que faz crescer com ela o pesquisador e a sociedade onde este se insere. Q uando o 'velho' narrador se recorda de temas recorrentes da infância, seja ela atual ou de outrora, quase sempre se evidenciam duas palavras: brincadeira e amizade. Talvez isso decorra do fato do brincar proporcionar amigos, e das amizades serem fortalecidas através das brincadeiras.

Diversos estudos (Rubin, 1980; Howes, 1996; G arcia 2005a; Garcia 2005b; Curtis, 2006) comprovam a veracidade dessa relação dialética, uma vez que, por meio das brincadeiras, as crianças criam eaumentam suaárea de contatos, aprendendo a se organizar e a atuar em grupo, experimentando diferentes papéis associados à cultura na qual vivem, identificando, assim, valores e costumes que transcendem 0 âmbito familiar.

As brincadeiras atraem as crianças logo nas fases iniciais do desenvolvimento infantil, etapas nas quais "quase todos os comportamentos [...] são suscetíveis de se converter em jogo, uma vez que se repitam por assimilação pura, isto é, por simples prazer funcional" (Piaget, 1964/ 1971, p. 117). D esse modo, o desenvolvimento ocorre como uma equilibração progressiva, permitindo que experiências externas sejam incorporadas pelo indivíduo, tendo em vista que o desenvolvimento é um processo de contínua construção da compreensão de uma realidade. Na brincadeira, a criança deforma o real para reconstruí-lo à sua maneira. Consequentemente, abrincadeiratem início quando aassimilação prevalece sobreaacomodação. Em outras palavras, "a brincadeira é caracterizada pela deformação e subordinação da realidade aos desejos do indivíduo" (Bichara, 1994, p. 17).

Segundo Friedmann (1996, p. 59), “0 resultado específico do pensamento seria atingir um equilíbrio permanente entre a assimilação do universo ao sujeito e a acomodação do sujeito aos objetos," de maneira que a realidade infantil estaria, de certa forma, adaptada às necessidades da criança. Nesse sentido, a criança é vista como o juiz de suas criações e opções enquanto brinca. No decorrer da brincadeira, as crianças entram em contato com signos e símbolos produzidos pela cultura à qual pertencem, aprendendo, questionando e interpretando-os. Evidencia-se que brincando se aprende a viver, uma vez que o brinquedo encerra 
em si significados e ideias peculiares. 0 brincar é, então, um processo que produz subjetividades.

Fica claro que ocorre uma bidirecionalidade da transmissão cultural, visto que a atividade de brincar é estruturada conforme o sistema de significado cultural relacionado ao contexto no qual está inserido. No entanto, essa mesma atividade "é reorganizada no próprio ato de brincar da criança, de acordo com o sentido particular por ela atribuído às suas ações, em interação com seus pares [...]" (Alves \& G noato, 2003, p. 03).

Dessa maneira, o fascínio da criança pelo brincar parece decorrer de sua percepção de que a essência da brincadeira está no constante 'fazer de novo', ou seja, na possibilidade contínua de recriação de si e do mundo ao qual pertence. Por conseguinte, a criança é agente de sua própria experiência de brincar, visto que, quando uma criança brinca, ela é obrigada a inventar soluções, tendo de ser criativa - fato que contribuiparao desenvolvimento daautonomiainfantil.

A amizade, por suavez, é uma das relações mais fundamentais na vida de uma criança. Segundo Garcia (2005a), a amizade na infância, ao lado da aceitação pelos pares, representa uma forma importante de socialização, com características próprias. D iante das transformações e das exigências da sociedade contemporânea ocidental, as crianças são expostas cada vez mais cedo e de modo mais intenso ao contato com os pares além do ambiente familiar.

É válido afirmar que as amizades ocorrem em redes sociais complexas, e que atuam como atenuadores das possíveis consequências de diversas situações negativas na vida das crianças envolvidas. Sob esse aspecto, pode-se afirmar que "a formação de redes de amizade facilita a inserção da criança no mundo que a rodeia" (Newcomb \& Bagwell, 1996, p. 291). Assim, a capacidade de cada criança tecer relacionamentos a partir de brincadeiras remete diretamente à sua capacidade de integração social.

Para Bukowski, Newcomb e Hartup (1996), as amizades formadas pelas crianças são um aspecto de seu desenvolvimento com implicações a longo prazo para sua adaptação em seu contexto social. Percebe-se, desse modo, que tanto a brincadeira como a amizade relacionam-se com a cultura. D essa maneira, conforme Carvalho ePontes (2003), partindo do pressuposto de que cultura é o conjunto de ações e consequências de ações humanas que, transmitidos de gerações a gerações, formam a identidade de um grupo humano, é lícito conceber a brincadeira como uma prática cultural, tendo como fundamento o ambiente no qual se constitui a identidade de seus membros.

Identifica-se, então, que na história humana há algumas ações que se repetem no decorrer das gerações - ainda que com características particulares - denominadas 'universais culturais', como regras de casamento, rituais de saudação, ritos funerários, tabus alimentares e receitas culinárias. D essa forma, o lúdico também se caracteriza como um universal cultural, uma vez que, "ainda que muitas vezes revestidas de uma roupagem idiossincrática, peculiar a uma determinada cultura, certas formas de brincar são reconhecidamente universais" (Carvalho \& Pontes, 2003, p. 18).

Embora muitas brincadeiras recebam a mesma denominação, ocorre em cada cultura um processo de singularização, segundo suas especificidades. Em outros casos, a mesma brincadeira recebe nomenclaturas diferentes, mas 0 teor é o mesmo. Trata-se da universalidade na diversidade. Tendo por base 0 fato de que a brincadeira é um fenômeno cultural e a criança é ativa na transmissão, elaboração e recriação dessa cultura, há uma natureza dialética e dinâmica integradaaumavisão bio-psico-social do ser humano no que diz respeito ao brincar.

A ssim, a brincadeira infantil é concebida, conforme afirma Kishimoto (1997), como um processo metafórico relacionado acomportamentos naturais e sociais. Todavia, ressalta-se que em grande parte das sociedades no mundo, o brincar faz parte da cultura como expressão de ideais e anseios. Nesse sentido, a assimilação da cultura intermediada pela brincadeira - detém uma função subjetiva, na qual a criança é capaz de resgatar, organizar e construir sua subjetividade, o que confere ao brincar uma influência direta sobre a compreensão da cultura em si.

D e acordo com D essen e Guedea (2005), o desenvolvimento e o desempenho do indivíduo ocorrem de modo integrado, mesclando recursos de maturação, experiência e cultura na ontogenia. D essa forma, é no processo de interação da pessoa com o meio que acontece o desenvolvimento dinâmico e contínuo. Assim sendo, o processo de interação engloba as relações do indivíduo com outras pessoas, com o ambiente que o cerca, com os grupos com os quais se relaciona, e com aspectos culturais - que se constituem de significados previamente estabelecidos e compartilhados. 
Diante dessas constatações, pretendeu-se descrever e relacionar o brincar, a amizade e a cultura, como uma tríade que se complementa. Acredita-se, dessa maneira, que a compreensão das funções sociais da brincadeira pode favorecer a integração entre diferentes culturas, próprias de cada nação.

Logo, como o ato de brincar e as amizades ocorrem em um determinado contexto cultural, a presente pesquisa optou estudar alemães, brasileiros e libaneses que viveram a infância em seu país de origem, e que atualmente residem no Estado do Espírito Santo. A Alemanha e o Líbano foram escolhidos por serem povos cujo movimento de imigração para o Brasil, em especial para o Estado do Espírito Santo, contribuiu para a formação do povo brasileiro/ capixaba, apesar de nem sempre serem lembradoscomo tal.A lém disso , o Brasilfoi selecionado por ser o país de destino dessas correntes migratórias e também como contraponto dos dados coletados.

Objetivou-se, portanto, descrever, comparar e analisar narrativas de lembranças de adultos alemães, brasileiros e libaneses sobre a interconexão entre brincadeira e amizade vivenciadas em suas infâncias e em suas respectivas culturas. Essa pesquisa teve como referência o trabalho de Bosi (1999; 2004), visto que seoptou em trabalharcomamemóriadosparticipantes, considerando que a rememoração recupera o tempo, faz variar o ponto de vista de quem fala, modificando a narrativa e redimindo a linguagem de hábitos cristalizados por tratar-se de um discurso flutuante. A narrativanão é, pois, somenteapenasumametodologia, mas sim uma forma de construção da realidade.

No mesmo sentido, a obra de Hinde (1997) serviu como base, especialmente em relação à amizade infantil explorada nesse trabalho com representantes da Alemanha, do Brasil e do Líbano. Têm-se, através do modelo sugerido pelo autor citado acima, que há relações dialéticas entre os relacionamentos (amizades infantis e demais formas de amizades), as estruturas socioculturais (ligadas às brincadeiras, entre outras atribuições) e 0 ambiente físico (que sofre as modificações do ser humano, incluindo os brinquedos e os aspectos geográficos e naturais do ambiente urbano, como a verticalização das moradias).

\section{MÉTODO}

Para compor a amostra do estudo, foi adotada amostragem não probabilística por acessibilidade e por tipicidade, de modo que foram entrevistados quatro indivíduos adultos de cada nacionalidade (alemães, brasileiros e libaneses).

Não houve análise acerca do nível social e escolar dos participantes. Não obstante, diante dos temas tratados, o gênero dos entrevistados foi considerado de acordo com a literatura específica sobre o tema, bem como segundo a menção feita pelos próprios participantes, tendo como fundamento seus costumes e tradições. Diante das características necessárias ao participante para integrar a pesquisa, manteve-se a faixa etária entre 40 e 70 anos, o que forneceu dados acerca de épocas diferentes do mesmo país, tanto entre os sujeitos da mesma nacionalidade, quanto em âmbito transcultural, de forma que o momento histórico do país de origem em questão foi considerado somente como base preliminar para a realização das análises.

Os participantes foram entrevistados individualmente, com base em um roteiro de entrevista contendo 16 questões, na qual se procurou abordar os seguintes aspectos, tendo porfundamento a substância social da memória infantil de cada entrevistado: aspectos culturais relacionados à pequena biografia de cada participante, lembranças e recordações da infância, características gerais e qualitativas das amizades e das brincadeiras, brincadeiras antigas em contraponto às atuais, e a relação entre brincadeira e amizade.

Os dados foram analisados de maneira qualitativa e organizados de acordo com a similaridade dos temas discutidos, conforme os assuntos acima expressos, procurando-se manter a estrutura narrativa fiel às respostas apresentadas. Com o intuito de manter em sigilo a identidade dos participantes, optou-se por utilizar nomes fictícios.

\section{RESULTADOS E DISCUSSÃO}

A título de melhor compreensão da apresentação dos resultados a seguir, optou-se em fazer a discussão ao mesmo tempo em que os resultados são apresentados, em virtude da íntima ligação entre os temas propostos, de acordo com a proposta de Bosi (1999; 2004), para quem a memória é um trabalho sobre o tempo vivido, conotado pela cultura e também pelo indivíduo; segundo a obra de Hinde (1997), no que concerne ao estudo do relacionamento; e tendo por base a utilização da análise de narrativa, conforme Jovchelovitch e Bauer (2002). 
Os participantes relataram suas lembranças acerca da infância, incluindo as atividades compartilhadas, as brincadeiras realizadas, os locais associados às amizades e a reflexão que fazem sobre a própria infância. De modo geral, alemães, brasileiros e libaneses recordaram-sedainfância com satisfação enostalgia, mesclando realizações com anseios que ficaram no porvir, afinal, segundo Bosi (2004, p. 20), "o tempo é, não homogêneo e vazio, mas repleto de índices."

Os participantes alemães, quando remetidos à infância, lembraram-se dos amigos e das atividades que realizavam juntos - na maioria das vezes eram brincadeiras -, bem como os brasileiros, cuja maior parte da amostra refere-se à infância como uma época de diversão aliada a trabalho intenso, uma vez que auxiliavam os pais no labor no campo. Os entrevistados libaneses, por sua vez, experimentaram a liberdade especialmente 0 gênero masculino - e a restrição delocomoção em virtude dos embates civis quando crianças, mediante a intensificação dos conflitos políticos e religiosos no país. Participantes alemães e brasileiros também destacaram que a amizade os auxiliou ao longo da vida, ensinando-os a transpor limites e a ajustar-se a novas situações.

De acordo com Rubin (1980), para crianças de todas as idades, mudanças de cidade, estado ou país acarretam dificuldades e ansiedades nos primeiros dias, até integrar-se às pessoas da nova região, formando novos amigos. Para crianças menores, tais mudanças são transpostas de modo mais fácil, pois as brincadeiras que realizam juntas, seja na escola, seja na vizinhança ou em qualquer outro lugar os aproxima, facilitando a formação de redes de amizade. Nesse contexto, evidencia-se que, através da brincadeira, de maneira natural e divertida, 0 indivíduo se torna capaz de entrar no mundo dacultura, das práticas sociais eda construção de si. Cercado por uma rede de amigos, sente-se mais seguro para agir e se portar diante de situações corriqueiras e novas, uma vez que acredita poder contar com aquelas pessoas escolhidas.

Áreas ao ar livre foram apontadas pelos participantes alemães e brasileiros como locais propícios à formação e ao cultivo de relações de amizade, pelo fato de terem proporcionado desco bertas e experiências que foram transformadas em diversão pelos amigos. Stela (alemã, 42 anos) destaca que "agenteiamuito no parque, as atividades eram muito ao ar livre, [...] uma vida bem solta," 0 que favorecia a integração com diversas pessoas, beneficiando a construção de relacionamentos interpessoais de amizade. D amesma forma, Adriana (brasileira, 53 anos) afirma que "[...] fora de casa fazia mais amizade." De fato, segundo Auhagen (1996), ambientes externos são favoráveis à formação de amigos. 0 gênero era bem demarcado no Líbano na época da infância dos participantes, de modo que havia diferença na forma de vivenciar essa fase da vida: aos meninos era permitido ampliar o leque de atividades eamizades aquém do ambiente familiar. Já as meninas possuíam círculos restritos de amizades e brincadeiras. Na maioria das vezes, as garotas só tinham as primas como amigas.

A criança quando brinca explora aspectos inesperados do real, amplia e aprofunda sua criatividade, construindo novas possibilidades para si mesma a partir dessa descontração durante 0 brincar. Nessesentido, os entrevistadosapresentaram brincadeiras, brinquedos e costumes lúdicos usualmente praticados por eles quando crianças em seus respectivos países de origem. Comentaram, também, no caso dos alemães e libaneses, que acreditam que viver a infância no Brasil há anos atrás era sinal de ter maior possibilidade de brincar.

Segundo os participantes alemães, cada momento de seu crescimento favoreceu um tipo de brincadeira, como brincadeiras com a boneca Barbie, jogos de tabuleiro confeccionados por mães e tias, e também jogos comprados prontos, pular elástico, brincar com carrinhos, aviões e pequenos bonecos simulando combates. G ostavam também de montar figuras concretas, encaixando-as como no L ego, dando forma à imaginação. Para eles, de acordo com aidade, o grupo de amigos desenvolvia brincadeiras condizentes ao que lhes interessava. Costumavam ainda montar bonecos de neve, descer de trenó e praticar esportes como natação, ski, windsurf e basquete com o grupo de amigos.

Soma-se a isso a questão dos climas da Alemanha e do Líbano, que determinavam algumas possibilidades debrincadeira entreas crianças. Nesse sentido, os participantes libaneses corroboram os alemães, afirmando que o clima do Brasil favorece a formação de amizades já que possibilita um maior número de brincadeiras e, em consequência, estimula a interação entre as crianças, gerando novos relacionamentos.

Na Alemanha, há grande preocupação em evitar que as crianças fiquem o tempo todo dentro dos recintos na estação fria: "você põe toda roupa possível 
e sai. Q uestão de saúde, questão de não ficar sempre só dentro" (Stela, alemã, 42 anos). No inverno, costumavam brincar de boneca, de jogos de tabuleiro, de pular elástico, com carrinhos, aviões e pequenos soldados. Gostavam também de montar figuras concretas, encaixando-as como no Lego, dando 'forma' à imaginação. Na opinião de Rodrigo (alemão, 45 anos), o frio típico do inverno alemão não atrapalhava a execução das brincadeiras, apesar de restringir algumas. Durante o verão, os amigos costumavam brincar na rua, andar de bicicleta, jogar amarelinha, pular corda, correr pelas plantações bosques, praticar esportes, pique-esconde e visitar os castelos para 'recontar' histórias. Além disso, era comum que as crianças frequentassem uma 'piscina comunitária' - já que era dever de todo alemão saber nadar.

Os participantes libaneses comentaram queusualmenteasmeninas brincavam com bonecas, de casinha, de cozinhadinho, amarelinha, pulacorda e queimada, e os meninos com pião, bolinha de gude, baralho e de praticar esportes diversos. Os participantes libaneses afirmaram que algumas brincadeiras, como queimada e baralho, eram realizadas por meninos e meninas, mas não juntos.

Em relação aos entrevistados brasileiros, comumente brincavam de queimada, pique-esconde, pula-corda, pipa, pião, amarelinha, bola de vidro e bolinha de gude, além de utilizar barro para criar bonequinhos. Conforme Lena (brasileira, 64 anos), "[...] eram brincadeiras saudáveis, e eu acho melhor que as de hoje." Adriana (brasileira, 53 anos), por sua vez, acredita que os papéis que assumia em algumas brincadeirasjáapresentavam traçosqueviriaaperceber em si mesma somente na vida adulta. Nesse contexto, Ruiz (1992, p. 23) afirma que "a atividade lúdica é uma preparação para a vida adulta. [...] A través do jogo de ficção, a criança [...] fantasia um mundo."

De maneira geral, meninos e meninas interagiam nas brincadeiras sem haver diferenciação nas atividades. De acordo com os participantes alemães e brasileiros, era permitido que ambos os sexos brincassem juntos. Entretanto, algumas brincadeiras faziam parte do repertório preferencial de cada um dos gêneros. Nota-se, assim, que a segregação entre gêneros nas amizades infantis está associada com a 'separação' dos brinquedos para os diferentes gêneros e também com as preferências individuais. Nesse sentido, para Friedmann (1996), a brincadeira abarca diversos enfoques, de forma que pode ser vista conforme o âmbito social no qual os grupos brincam.
Logo, pode-se destacar a contribuição da brincadeira para a educação e para a aquisição de conhecimento, visto que no âmbito psicológico o brincar facilita a compreensão do funcionamento psíquico, emotivo e da personalidade do indivíduo, refletindo, em cada sociedade, os costumes e a história de diversas culturas. Fica claro, portanto, que a brincadeira é concebida amplamente como expressão da cultura infantil.

Identifica-se, então, quecada geração possui amemóriadeacontecimentosque permanecem como pontos de demarcação em sua história. D estarte, as gerações passadas continuamente têm a intenção de auxiliar as gerações presentes a partir de suas experiências. Segundo Bosi (2004, p. 16), “do vínculo com o passado se extrai a força para formação de identidade". Há, assim, uma memória coletiva que é produzida por cada grupo de amigos durante anos e difundida ao longo de suas vidas. D essa forma, a criança recebe das outras gerações não apenas dados históricos, mas aspectos culturais e sociais, à medida que aprofunda suas raízes nas histórias vividas por seus ascendentes.

Corroborando estudos anteriores (Rubin, 1980; Boreli, Garcia, 2006), as três nacionalidades descritas neste trabalho apontam, em graus diferentes, exatamente os mesmos grupos destacados na literatura sobre o tema como principais fontes de origem das amizades, facilitadores de interações infantis e também como incentivadores da manutenção desses relacionamentos: a escola, a vizinhança e a família. A crença religiosa em comum também foi apontada pelos participantes como facilitadora da formação de amigos.

$\mathrm{Na}$ opinião dos entrevistados libaneses, as amizades se formavam principalmenteno reduto familiar, sob a influência dos pais. Em menor escala, podiam ter amigos na escola, sendo que estes se restringiam ao período escolar, bem como os amigos da Igreja. Os entrevistados alemães enfatizaram a escola como propiciadora de amizades, ainda mais pelo fato dos pais tornaremse amigos dos pais dos amigos de seus filhos, ampliando o convívio das crianças para além do ambiente escolar. O s participantes brasileiros, por sua vez, apontaram os arredores de suas casas como possibilidades de fazer amigos: "é... mais pela redondeza mesmo. Bairros adjacentes ali, né, vizinhos, no caso" (Joaquim, brasileiro, 40 anos). Para eles, os amigos da escola, na maioria das vezes, restringiam-se ao ambiente escolar e os 
familiares, em especial os primos, eram companhias constantes nas férias escolares.

Também segundo diversos estudos (Krappmann, 1996; Newcomb, Bagwell, 1996; Garcia, 2005a; Curtis, 2006), crianças tendem a se tornarem amigas de outras do mesmo sexo, detamanho parecido, com idades semelhantes e no mesmo 'degrau' de maturidade psíquica, apresentando interesses em comum. Mesmo em países com aspectos políticos e culturais bem diferentes, a maioria das crianças opta e busca auxílio em parceiros do mesmo gênero, desenvolvendo, assim, intimidade. Dessa forma, características semelhantes apresentam-se como facilitadoras dos relacionamentos amigáveis tanto em suaformação como em seu prolongamento.

As três nacionalidades descritas nesta pesquisa enfatizaram aspectos e lembranças positivas das amizades infantis e ressaltaram a importância da amizade na formação da criança como indivíduo. Afirmaram que os amigos de infância foram de suma importância em suas vidas, pois aprenderam a partir das interações e das experiências que vivenciavam juntos. Nesseínterim, segundo Rubin (1980, p. 44) "o que importa, é como a criança utiliza a amizade para se constituir" .

Em comum, os participantes alemães declararam que as amizades ficaram marcadas por terem sido intensas, duradouras e com comprometimento entre os amigos, o que proporcionava boas experiências e que hoje permite agradáveis recordações.Jáos participantes brasileiros clarificaram que as amizades de antigamente eram mais bem aproveitadas do que as de hoje, uma vez que "[...] tinha liberdade" (Lena, brasileira, 64 anos). Destarte, identifica-se que as características fundamentais paraos libaneses considerarem alguém como amigo eram o auxílio recíproco, a honestidade, a simpatia, alealdade e a uniformidade de interesses.

Nota-se que cada cultura desenvolve sua própria maneira de compreender e vivenciar a amizade. Assim, as especificidades de cada nação em relação ao modo de conceber a amizade geram expectativas e interpretações particulares sobre as experiências com os relacionamentos. Não há igualdade plena entre os países em qualquer âmbito que seja. Existem diferentes crenças, normas comportamentais, regras sociais, organizações físicas e estruturais, tradições cognitivas e religiosas, escritas de acordo com a história de cada nação. Tais peculiaridades tornam cada nação única no cenário mundial.
Em relação aos aspectos qualitativos da amizade, por exemplo, os participantes libaneses pouco se expressaram. Prezavam e ainda anseiam pela sinceridade, pelo desprendimento e pelo carinho em seus relacionamentos interpessoais. Os entrevistados alemães mostraram-se mais cautelosos e racionais do que os brasileiros e libaneses na escolha de uma pessoa que pudesse vir a se tornar amiga.

Evidencia-se, ainda, que a amizade é concebida de formas diferentes em cada fase da vida. Para Garcia (2005a, p. 07), "a natureza e 0 conteúdo de suas amizades se transformarão com 0 passar do tempo. As amizades, contudo, sempre terão um caráter espontâneo e uma liberdade que não encontrará dentro dafamília." 0 vínculo criado a partir da intimidade entre amigos tende a ser duradouro, ainda que não haja regras que definam a duração ou a interrupção de amizades. Todavia, as vicissitudes da amizade em alguns momentos podem produzir também ansiedades e angústias.

Houve unanimidade entre os participantes das diferentes culturas descritas nessa pesquisa, considerando-se as particularidades de cada um, no que concerne à existência de uma relação direta entre brincadeira e amizade. Todos eles ressalvaram que há maior facilidade em se formar amizades por meio de brincadeiras. D estarte, identifica-se que a brincadeira encoraja a interação na medida em que, pormeio do brincar, épossível representar, despertar emoções e promover identificação, seja por meio subjetivo, seja através de outras pessoas.

D estaca-se, contudo, que 0 ato de brincar e a formação de amizades ocorrem em um âmbito cultural. Dessa forma, "o contexto cultural tem uma presença importante na ação lúdica" (Ruiz, 1992, p. 25), de modo que cada cultura étransmitida, compreendida e, acima de tudo, experienciada através das brincadeiras.

Os participantes alemães, brasileiros e libaneses assemelham-se muito no que concerne à relação entre o intercâmbio de sentimentos e as experiências propiciadas pelas brincadeiras entre os envolvidos. Para Júlia (brasileira, 60 anos) “[...] através da brincadeira faz amizade", à medida que é possível conhecer novas pessoas em situações de brincadeira, da mesma forma que para Rodrigo (alemão, 45 anos), para quem "brincar junto faz amigo". Ainda conforme Júlia (brasileira, 60 anos), a partir das experiências trocadas durante as brincadeiras, é possível selecionar os amigos por afinidade e por similaridade, destacando que, " [...] 
se duas crianças não brincar junto, não vai descobrir nunca se vai gostar da outra ou não."

De modo geral, os participantes brasileiros argumentam que iniciar um relacionamento de amizade por meio de brincadeiras permite que sentimentos sinceros emerjam entre os participantes, criando relações de confiança, sinceridade e fidelidade. A liberdade de escolha, tão característica das relações de amizade, é destacada por Lena (brasileira, 64 anos), uma vez que, brincar entre amigos "[...] faz com que a gente fique mais junto, mais unido, e vai construindo, vai formando o nosso caráter, né?!."

Da mesma maneira, os entrevistados alemães acreditam que a brincadeira é fundamental tanto na formação como na manutenção das relações de amizade, visto queaproxima as pessoas. Para Marina (alemã, 64 anos), os momentos lúdicos são capazes de criar vínculos intensos entre os envolvidos, de forma que afirma que as amizades criadas na infância através das brincadeiras são a "[...] base todinha da formação da criança".

De modo análogo, os participantes libaneses afirmam que os amigos se aproximam em virtude das brincadeiras que realizam juntos. Acreditam que 0 estreitamento das amizades ocorre conforme se intensifica o contato entre os participantes das brincadeiras. Argumentam que as brincadeiras necessitam de espaço e tranquilidade para acontecerem, de maneira que asseguram "[...] que aqui no Brasil é mais fácil ser criança, ter amigos e brincar, porque não existe esse clima de rivalidade religiosa" (Jânio, libanês, 69 anos).

Participantes alemães, brasileiros e libaneses alegaram que a ajuda mútua e o exercício da cooperação propiciados em ambientes de brincadeiras favorecem a criança, a compreensão da 'realidade', além de ensinamentos de modos possíveis de atuação. Em contrapartida, nos dias atuais observa-se um esvaziamento da cultura material elocal em sua relação com o brincar em um mundo globalizado, no qual tudo parece próximo e possível. D essa maneira, "o brincar é o modo mais importante de apropriação do mundo e tem de ocorrer a partir de possibilidades reais para gerar uma 'ilusão' criativa e prazerosa, e não uma ilusão enganosa" (Rabinovich, 2003, p. 29).

Praticamente todos os entrevistados não contavam com instrumentos tecnológicos, de modo que os envolvidos nas brincadeiras criavam seus próprios brinquedos e, quando adquiriam algum, compartilhavam-no com os amigos. Os próprios participantes da pesquisa, com destaque para os alemães e os brasileiros, afirmaram que havia menos egoísmo entre as crianças antigamente.

Os participantes libaneses em especial, enfatizaram também que a brincadeira é responsável pela formação psíquica da pessoa: "trabalha muito o psicológico da pessoa, ainda mais criança. Forma muito o psicológico, o domínio" (Hercília, libanesa, 59 anos). Para ela, cada atividade lúdica exige concentrações e atitudes peculiares para sua boa execução. A partir daí, coordenações e comportamentos favorecerão o convívio com os demais, criando redes de amizade que crescerão e serão aprofundadas de acordo com o contato promovido pelas brincadeiras.

D urante a brincadeira, a criança - ou 0 adulto - participante pode experimentar normas definidaspela sociedade, bem como variações dessas normas. É lícito que escolha entre aceitar e/ ou recusar certas convenções, promovendo sua construção pessoal. Por meio da brincadeira, a criança experimenta diferentes sensações: prazer, alegria, liberdade de pensamento, treino para a vida adulta e possibilidades de criação. Com as criações possíveis no brincar, desenvolve-se a criticidade e a autoconfiança, por exemplo.

Os participantes alemães argumentaram que a magia tão inerente à infância tem se dissipado ao longo dos anos, em diversos momentos e independente da cultura. Stela (alemã, 42 anos) ressalta que naAlemanha de suainfância, brinquedos industrializados e manufaturados se misturavam à criatividade das crianças para vivificarem esses objetos. Entretanto, argumentam que as crianças fixam-se nos aparatos tecnológicos, reduzindo sua capacidade criativa e criadora. Declaram ainda que as brincadeiras de antigamente eram mais saudáveis, uma vez que viabilizavam relacionamentos interpessoais e geravam aprendizagens que seriam rememoradasao longo davida. Naopinião de Rodrigo (alemão, 45 anos), " as brincadeiras hoje são jogo no computador, não? [...] São jogos que joga sozinho. [...] Ah... Não bom para saúde, não bom para fazer amigos, não bom para aprender relação."

Nota-se que os participantes alemães mostram-se preocupados com o isolamento que os brinquedos e também as brincadeiras estimuladas na sociedade atual têm proporcionado. Identificase ainda, que questionam a falta de cuidado e de sensibilidade com a infância atual. O s participantes 
brasileiros e em menor escala os libaneses corroboram tais opiniões, ponderando que algumas características e atividades aprendidas a partir de situações de brincadeira contribuíram efetivamente para suas escolhas e funções profissionais.

Segundo os entrevistados brasileiros, aproveitavam os recursos naturais disponíveis na companhia dos amigos e 'abusavam' da criatividade, criando brincadeiras inesquecíveis, o que as tornavam mais interessantes que as de hoje. Júlia (brasileira, 60 anos) resume a opinião dos demais participantes brasileiros acerca da comparação entre a infância que tiveram e as que visualizam atualmente, assegurando que "eu acho que a minha infância foi mais tranquila, mais bem aproveitada. M esmo que eu trabalhei muito e não tive oportunidade de estudar [...]."

Os entrevistados libaneses pouco relataram sobre a vivência da infância. No que se refere aos brinquedos, balanceavam criatividade e praticidade. Geralmente as meninas criavam suas próprias bonecas e usavam alguns materiais disponíveis no local para criarem o cenário lúdico. Por outro lado, os participantes libaneses do gênero masculino destacaram que foi possível brincar com os amigos na rua quando eram crianças. Contudo, diante da situação política e religiosa do país, brincadeiras ao ar livre não são mais corriqueiras no Líbano, uma vez que os libaneses tiveram que se adaptar às condições impostas pelos conflitos.

Em contrapartida, as maiores identificações entreostrêsgruposparticipantesocorreram em termos qualitativos. Em uníssono, afirmaram que a qualidade da infância que tiveram foi muito superior à que as crianças vivem atualmente, pelo fato de haver maior cumplicidade, sinceridade, confiança e afeto entre os amigos participantes das brincadeiras. Como muitas brincadeiras recorrentes na sociedade vigente envolvem poucas pessoas ou somente uma, acreditam que tem havido grande redução afetiva e amigável entre as crianças. Além disso, apontaram que há certo apagamento da singularidade, seguido de uma artificialização do brinquedo, em decorrência do consumismo exacerbado e do imediatismo moderno.

Sob esse aspecto, a brincadeira sinaliza a diversificação possível de atribuições e sua relação com o ambiente cultural ao qual tem acesso, e demonstra também a onipresença do processo identificatório subjacenteatais atribuições. Ressaltase, dessa forma, que as propriedades dos brinquedos estão associadas às características culturais de cada lugar. O brinquedo atua, então, como um espelho no qual a criança reflete a construção de sua identidade, ao mesmo tempo em que reproduz a dos modelos que contribuem para formá-la.

De modo geral, apesar dos participantes das três nacionalidades envolvidas nesse estudo considerarem que a inserção tecnológica angariou benefícios à sociedade, ficou claro que eles contestam os modos de utilização desses recursos. Identifica-se em todos os participantes dessa pesquisa certa nostalgiaao recordarem suas brincadeiras deinfância, de maneira que valorizaram suas atividades, a forma como realizavam as brincadeiras, os locais nos quais brincavam, a responsabilidade que tinham quando criança - mas que não os impedia de brincar - e até mesmo a restrição que havia para obter algum brinquedo industrializado, em detrimento do que assistem da infância atual.

Em poucos momentos os entrevistados destacaram pontos positivos da infância dos últimos anos. Reconhecem e valorizam a importância dos recursos tecnológicos, todavia, contra-argumentam que a facilidade em conseguir informações hoje em dia contribui paraa desmistificação da magia própria das crianças de sua época.

\section{CONSIDERAÇÕES FINAIS}

A presente pesquisa destacou, dentre outros aspectos, que a brincadeira favorece a formação de relacionamentos de amizade, bem como atua como mediadora na manutenção de tais relações. Por conseguinte, objetivou-se descrever, comparar e analisar a brincadeira e sua relação com a amizade de acordo com a cultura de alemães, brasileiros e libaneses, a partir de suas recordações. Com a realização da presente pesquisa, tornou-se possível evidenciar que a brincadeira é uma atividade de suma importância para a formação de novos relacionamentos de amizade e suas subsequentes atribuições.

Partiu-se de uma exposição geral do tema, para identificar, descrever e analisar elementos constitutivos e desencadeadores da relação entre brincadeira e amizade, levando-se em consideração o âmbito no qual ocorriam esses fenômenos sociais. De modo análogo, verificouse a dialética entre o brincar e o ser amigo na visão de alemães, brasileiros e libaneses que se recordaram de sua infância para transformaremna em relatos orais. 
A partir desses objetivos, buscou-se demonstrarqueabrincadeira, em suaíntima relação com a cultura, pode ser considerada como produto e produtora de ações humanas, que transmitidas de geração a geração denotam identidades grupais e pessoais. Mais do que isso, a motivação originada pelo ato de brincar faz parte - direta e efetivamente - de todo um contexto de vida que, por sua vez, ilumina a arte de brincar.

A brincadeirapodeserpensadatanto como um comportamento adaptado como adaptativo do ser humano. Constata-se queéconsideradaadaptada por ser comum a todos os membros da espécie; e adaptativa, uma vez que, se todos da espécie brincam, varia como, onde, com quem e com que brincam, isto é, se diversifica segundo o contexto cultural e social.

Indubitavelmente, a infância de outrora se diferencia da atual, e sempre será assim. 0 ser humano - agente e produto da cultura - reinventase continuamente. Nos dias atuais, com a velocidade dasinformações, novasformas deatuação no mundo e novas atividades são desenvolvidas e podem ser aprendidas a todo instante. No entanto, é fato que a brincadeira proporciona à criança momentos de autonomia, de autodeterminação, de liberdade e de escolha de seu agir no mundo, tornando-a agente de sua própria vida e de seu desenvolvimento.

O presente estudo clarificou como a amizade e o brincar - expressões humanas atuantes em diferentes culturas - estão relacionados, e demonstrou que fatores do ambiente e da cultura fazem a mediação entre 0 brincar e a amizade. Assim sendo, as brincadeiras tomam objetos do meio ambiente e lhe atribuem um significado particular, e as próprias brincadeiras fazem a interligação entre os amigos.

A través dos relatos dealemães, brasileiros e libaneses, foi possível reconhecer a unanimidade na diversidade, as incríveis semelhanças que ultrapassam oceanos, as divergências que apenas secomplementam. A memória oral revelou detalhes da história particular, que pode ser compreendida sob a luz da história da humanidade.

Nota-se, dessa forma, que a mediação do brincar pela amizade - apesar das suas variações culturais - representa não somente uma condição atuante nas diversas tradições, mas permite a comunicação entre esses costumes, contribuindo para que imigrantes sintam-se acolhidos no seio cultural da nação que escolheram para viver.
Clarificou-se também, que alemães, libaneses e demais imigrantes trouxeram seus costumes de origem, porém respeitam e valorizam a cultura que encontraram aqui no Brasil.

Hoje em dia, de modo amplo, se reconhece a importância da brincadeira, incentivando-a. Até poucos anos atrás, a brincadeira era concebida como uma atividade para a criança desocupada, sem aulas de natação, balé ou línguas para frequentar. Voltando um pouco mais no tempo, tendo por base a sociedade ocidental, a brincadeira era substituída pelo trabalho no campo, a fim de auxiliar os pais. O bserva-se que 0 brincar ganhou espaço ao longo dos anos.

Assim, diversas brincadeiras preservam a estruturainicial, outras semodificam e outras surgem no universo. A força e 0 alcance das brincadeiras trazem consigo muito dauniversalidade tipicamente humana, bem como trazem a especificidade construída ao longo dos anos. Em meio a essas brincadeiras, laços afetivos são formados, podendo existir por toda a vida, ou existindo apenas por algum tempo. 0 fato é que as lembranças ficarão. Algumas em maior grau para uns, outras em menor escala para outros. O que importa é que todos brincam, aprendem, compreendem, sedesenvolvem, erram, constroem e buscam a si mesmos nas mais adversas situações.

Portanto, brincar é preciso não apenas pelas consequências funcionais no desenvolvimento deuma pessoa, ainda que tais ocorrências decorram naturalmente do brincar enquanto atividade espontânea e automotivada. É preciso brincar para conhecer. É preciso brincar porque se é humano. É preciso brincar para ser humano. O u deveria ser assim.

Apoio financeiro: Coordenação de Aperfeiçoamento de Pessoal de Nível Superior CAPES.

\section{REFERÊNCIAS}

Alves, A. M. P., \& G noato, G. (2003). O brincar e a cultura: Jogos e brincadeiras na Cidade de Morretes na década de 1960. Psicologia em Estudo, 8(1), 111-117.

Auhagen, A. E. (1996). Adult friendship. In A. E. Auhagen, \& M. Von Salich (O rg.). The diversity of human relationships. (pp. 229247). Cambridge: Cambridge University Press. 
Bichara, I. D. (1994). Um estudo etológico da brincadeira de faz-de-conta em crianças de 3 a 7 anos. D issertação de Mestrado, Pontifícia Universidade Católica de São Paulo, São Paulo.

Boreli, M. T. B., \& Garcia, A. (2006). Psicologia da amizade na infância: uma investigação empírica na cidade de Vitória. In A. Garcia (O rg.). Relacionamento interpessoal: Estudos brasileiros. (pp. 67-81). Vitória: UFES.

Bosi, E. (1999). Memória e sociedade: Lembranças de velhos. São Paulo: Companhia das Letras.

Bosi, E. (2004). 0 tempo vivo da memória: Ensaios de psicologia social. São Paulo: Ateliê Editorial.

Bukowski, W. M., Newcomb, A. F., \& Hartup, W. W. (1996). Friendship and its significance in childhood and adolescence: introduction and comment. In W. M. Bukowski, A. F. Newcomb, \& W. W. Hartup. The company they keep: Friendship in childhood and adolescence. (pp. 01-15). Cambridge: Cambridge University Press.

Carvalho, A. M. A., \& Pontes, F. A. R. (2003). Brincadeira é cultura. In A. M. A. Carvalho et al. (O rg.). Brincadeira e cultura: Viajando pelo Brasil que brinca - o Brasil que brinca. (pp. 15-30). São Paulo: Casa do Psicólogo.

Curtis, A. (2006). O brincar em diferentes culturas e em diferentes infâncias. In: J. R. Moyles. A excelência do brincar. (pp. 3949). Porto Alegre: Artmed.

Dessen, M. A., \& Guedea, M. T. D. (2005). A ciência do desenvolvimento humano: ajustando o foco de análise. Paidéia Cadernos de Psicologia e Educação, 15(30), 11-20.

Friedmann, A. (1996). Brincar: Crescer e aprender - o resgate do jogo infantil. São Paulo: Moderna.

Garcia, A. (2005a). Psicologia da amizade na infância: Uma introdução. Vitória: Núcleo Interdisciplinar para o Estudo do Relacionamento Interpessoal.

Garcia, A. (2005b). Relacionamento inter-pessoal: Uma área de investigação. In A. G arcia. Relacionamento interpessoal: 0 lhares diversos. Vitória: UFES, Programa de PósG raduação em Psicologia.
Hinde, R. A. (1997). Relationships: A dialectical perspective. London: Psychology Press.

Howes, C. (1996). The earliest friendships. In W. M. Bukowski, A. F. Newcomb, \& W. W. Hartup (Ed.). The company they keep: Friendship in childhood and adolescence. (pp. 66-86). Cambridge: Cambridge University Press.

Kishimoto, T. M. (1997). O jogo e a educação infantil. In T. M. Kishimoto. Jogo, brinquedo, brincadeira e a educação. (pp. 07-44). São Paulo: Cortez.

Krappmann, L. (1996). A micitia, drujba, shin-yu, philia, freundschaft, friendship: on the cultural diversity of a human relationship. In W. M. Bukowski, A. F. Newcomb, \& W. W. Hartup (Ed.). The company they keep: Friendship in childhood and adolescence. (pp. 19-40). Cambridge: Cambridge University Press.

Newcomb, A. F., \& Bagwell, C. L. (1996). The developmental significance of children's friendship relations. In W. M. Bukowski, A. F. Newcomb, \& W. W. Hartup (Ed.). The company they keep: Friendship in childhood and adolescence. (pp. 289-321). Cambridge: Cambridge University Press.

Jovchelovitch, S., \& Bauer, M. W. (2002). Entrevista Narrativa. In M. W. Bauer, \& G. Gaskell (Ed.). Pesquisa qualitativa com texto, imagem e som: Um manual prático. Rio de Janeiro: Vozes.

Piaget, J. (1971). A formação do símbolo na criança: Imitação, jogo, sonho, imagem e representação. Rio de Janeiro: Zahar. Publicado originalmente em 1964.

Rabinovich, E. P. (2003). Nos tempos dos avós. In A. M. A. Carvalho, C. M. C. Magalhães, F. A R. Pontes, I. D. Bichara. (O rg.). Brincadeira e cultura. Viajando pelo Brasil que brinca: Brincadeiras de todos os tempos. (Vol. 2, pp. 09-30).São Paulo: Casa do Psicólogo.

Rubin, Z. (1980). Children's friendship. Massachusetts: Harvard University Press.

Ruiz, R. O. (1992). El juego infantil y la construcción social del conocimento. Sevilla: Alfar.

Recebido: 14/ 05/ 2008

Received: 05/ 14/ 2008

Aprovado: 29/07/ 2008

A pproved: 07/ 29/ 2008 